\title{
Simulating seismically isolated buildings under earthquake-induced pounding incidences
}

\author{
P. C. Polycarpou \& P. Komodromos \\ Department of Civil and Environmental Engineering, \\ University of Cyprus, Nicosia, Cyprus
}

\begin{abstract}
Seismically isolated buildings usually experience large horizontal relative displacements during strong earthquakes due to the flexibility that is incorporated, through seismic bearings, at their bases. If the available clearance around a seismically isolated building is, for any reason, limited, then there is a possibility of the building pounding against adjacent structures. This paper, presents a methodology for simulating this problem using numerical methods, in order to investigate the effects of potential pounding on the overall seismic response of seismically isolated buildings.
\end{abstract}

Keywords: seismic isolation, earthquake, pounding, impacts.

\section{Introduction}

Seismic isolation is usually based on the incorporation of flexible elastomeric bearings, typically at the base of a building, in order to shift its fundamental period outside the dangerous for resonance range of periods and avoid resonance with the induced earthquake excitation. However, strong seismic actions cause large horizontal relative displacements at the isolation level of seismically isolated structures due to the excessive flexibility that is provided through the seismic bearings. Therefore, a wide clearance, known as "seismic gap", must be provided around a seismically isolated building in order to accommodate the expected large horizontal displacements during a strong earthquake. Nevertheless, the width of the provided seismic gap cannot be unlimited due to practical constraints, especially in cases of retrofitting existing structures. In addition, it is widely accepted that there are several uncertainties about the characteristics of the expected earthquake and the methods of estimating the 
induced relative displacements of the building. Thus, a reasonable concern is the possibility of poundings of a seismically isolated building against either the surrounding moat wall or adjacent buildings during a very strong earthquake.

Earthquake induced pounding incidences between fixed-supported buildings, motivated relevant research in the past [1-5]. However, very limited research work has been carried out for poundings of multi-storey seismically isolated buildings [5-8], which exhibit quite different dynamic characteristics from fixedsupported buildings. Specifically, poundings of a seismically isolated building occur primarily as a result of the large relative displacements at the isolation level (Figure 1), while in the case of conventionally fixed-supported buildings, poundings occur due to the deformations of the superstructure, usually at the building tops. Moreover, it is more likely to have more demanding performance requirements and higher expectations for buildings that utilize an innovative earthquake-resistant design, such as seismic isolation, than for conventionally fixed-supported buildings.

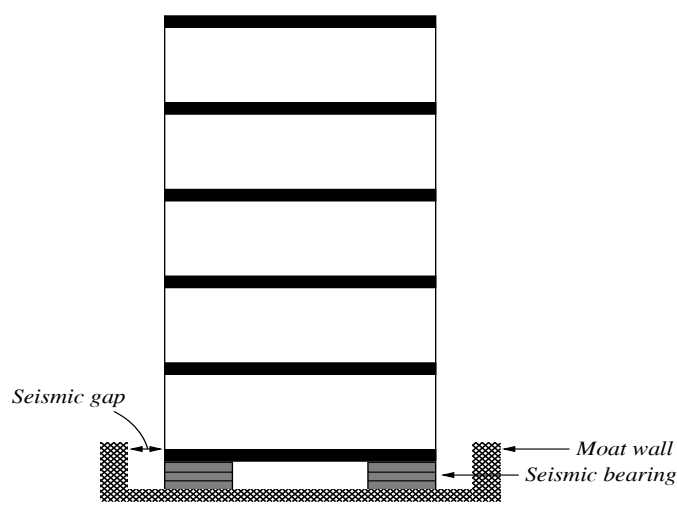

(a)

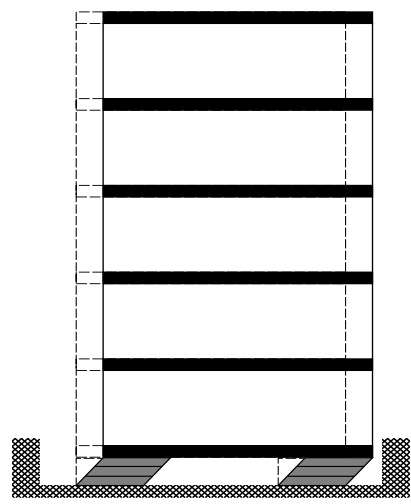

(b)

Figure 1: (a) Configuration of a seismically isolated building; (b) Mode of deformation during an earthquake.

This paper presents a simple methodology for the numerical simulation of seismically isolated buildings that undergo earthquake excitations with the possibility of impact occurrences.

\section{Methodology}

The modelling of the simulated structures is performed in two dimensions (2D), while the multi-storey buildings are modelled as multi-degree of freedom (MDOF) systems, with shear-beam behaviour and the masses lumped at the floor levels, assuming linear elastic behaviour during earthquake excitations. A bilinear model is used for the simulation of the isolation system's behaviour, which corresponds to the use of Lead Rubber Bearings (LRB). In particular, prior to the yielding of the lead core, the isolation system has an initial stiffness 
$K_{l}$, which is much higher than the post-yield stiffness $K_{2}$ that corresponds solely to the stiffness of the rubber.

\subsection{Impact modelling}

The numerical modelling of impact and the estimation of the impact forces acting on the colliding bodies is an essential topic, not only for the cases of structural poundings, but also for other problems involving numerical simulation of impact. Usually, in numerically simulated dynamic systems, such as multistorey buildings under earthquake excitations, structural impact is considered using force-based methods, also known as "penalty" methods. These methods allow small interpenetration between the colliding structures, which is justified by their deformability at the vicinity of the impact. Contact springs are automatically formed when an impact is detected, kept as long as the colliding bodies remain in contact and removed as soon as the bodies are detached from each other. The interpenetration depth is used together with the stiffness of the contact spring to estimate, according to the impact model, the contact forces that are applied to the structures, pushing them apart. There are either linear or nonlinear impact models, depending on whether the impact force is increasing linearly or exponentially with the indentation.

In the current study, the modified linear viscoelastic impact model [7] is used, assuming an impact spring and an impact dashpot exerting, in parallel, impact forces to the colliding structures whenever their separation distances are exceeded. Actually, it is a small variation of the classical Kelvin-Voigt impact model, in which the tensile forces arisen at the end of the restitution period are omitted and a small plastic deformation is introduced, which increases the available clearance (Figure 2). In particular, when a contact is detected, the impact force is estimated at each time-step using the following formulas:

$$
F_{i m p}(t+\Delta t)=\left\{\begin{array}{cl}
k_{i m p} \cdot \delta(t)+c_{i m p} \cdot \dot{\delta}(t) & \text { when } \quad F_{i m p}(t)>0 \\
0 & \text { when } F_{i m p}(t) \leq 0
\end{array}\right.
$$

where $\delta(t)$, is the interpenetration depth, $\dot{\delta}(t)$ is the relative velocity between the colliding bodies, $k_{\text {imp }}$ is the impact spring's stiffness and $c_{i m p}$ is the impact damping coefficient. The later is computed according to the following formulas, provided by Anagnostopoulos [1], and based on the conservation of energy before and after impact:

$$
\begin{gathered}
c_{\text {imp }}=2 \cdot \xi_{i m p} \sqrt{k_{i m p} \frac{m_{1} \cdot m_{2}}{m_{1}+m_{2}}} \\
\xi_{i m p}=-\frac{\ln (\mathrm{COR})}{\sqrt{\pi^{2}+(\ln (\mathrm{COR}))^{2}}}
\end{gathered}
$$


In the above formulas, $m_{1}, m_{2}$ are the masses of the two colliding bodies and $C O R$ represents the coefficient of restitution which is defined as the ratio of relative velocities after and before impact $(0<C O R \leq 1)$. The exact value of the impact stiffness term $\left(k_{i m p}\right)$ is practically unknown, since its physical meaning is not clearly determined. However, it seems that its value depends on the mechanical properties of the material and the geometry of the contact surface of the colliding bodies. For the simulations in the current study the value of 2500 $\mathrm{kN} / \mathrm{mm}$ has been chosen for the impact stiffness, while the COR is assumed to be equal to 0.6 .
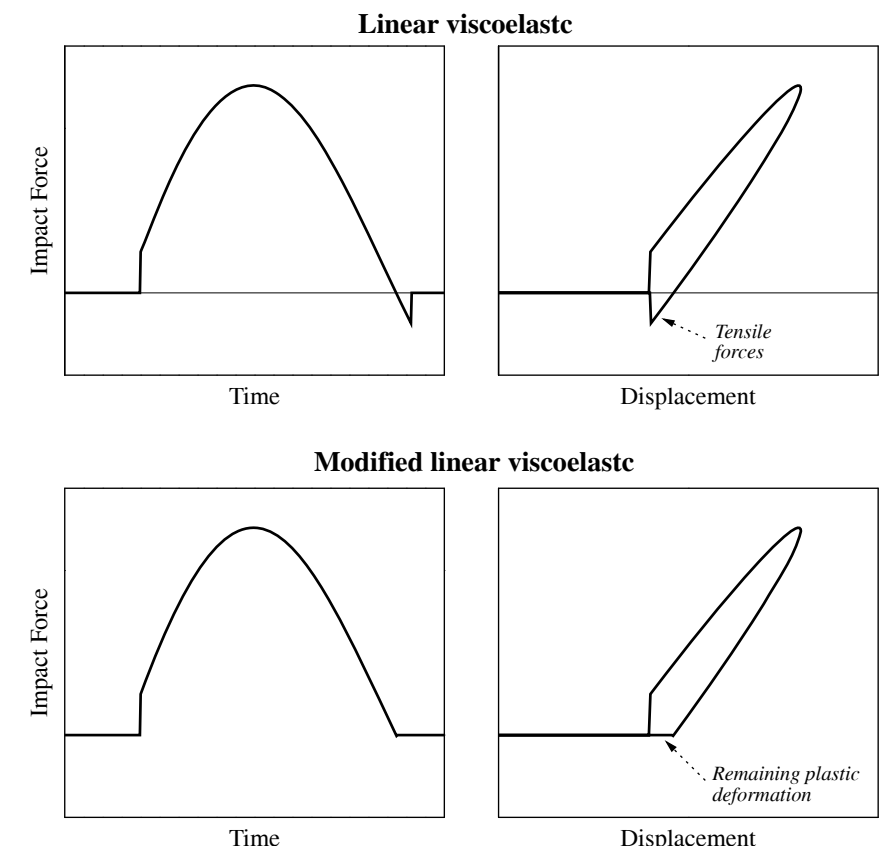

Figure 2: The classical Kelvin-Voigt impact model and the modified linear viscoelastic impact model.

\subsection{Equations of motion}

The differential equations of motion for a seismically isolated building, which is modeled as a MDOF system, are expressed in the following matrix form:

$$
\underline{F}^{I}(t)+\underline{F}^{D}(t)+\underline{F}^{E}(t)=\underline{0}
$$

where $\underline{F}^{I}, \underline{F}^{D}$ and $\underline{F}^{E}$ are the inertia, damping and elastic forces, respectively, acting on the structure at time $t$. In the case of a ground excitation with an acceleration time-history $\ddot{U}_{g}(t)$, the inertia forces are expressed as:

$$
\underline{F}^{I}(t)=\underline{M} \cdot \underline{\ddot{U}}(t)+\underline{M} \cdot \underline{\imath} \cdot \ddot{U}_{g}(t)
$$


where $\underline{l}=\left[\begin{array}{llll}1 & 1 & \cdots & 1\end{array}\right]^{T}$. The damping forces are expressed in terms of the floor velocities and the damping matrix of the MDOF system:

$$
\underline{F}^{D}(t)=\underline{C} \cdot \underline{\dot{U}}(t)
$$

The elastic forces $\left(\underline{f_{s}}\right)$ of the superstructure are computed based on the stiffness matrix and the corresponding displacements at time $t$, while for the seismic isolation system the elastic forces are calculated according to the bilinear model considering the displacement time-history $u(t)$ and the velocity sign at the isolation level at time $t$ :

$$
\underline{F}^{E}(t)= \begin{cases}\underline{f_{s}}(u(t), \dot{u}(t)) & \text { no impact } \\ \underline{f_{s}}(u(t), \dot{u}(t))+\underline{e} \cdot F_{i m p}^{E}(t) & \text { during impact }\end{cases}
$$

$F_{i m p}^{E}(t)$ and $F_{i m p}^{D}(t)$ are the elastic and damping contact forces during impact, respectively, which are calculated according to the corresponding impact model. The impact forces are non-zero only whenever the relative displacements at the corresponding level, along the height of the simulated building, exceed the available clearance, leading to poundings with the adjacent structure. Each of the terms $e_{i}$ of vector $\underline{e}$, which has a dimension equal to the number of the degrees of freedom, is equal to 0 when no contact is detected in DOF $i$, while it takes the value of 1 when an impact occurs in the corresponding floor. The equations of motion are directly integrated using the Central Difference Method (CDM), computing the displacements at time $(t+\Delta t)$.

\subsection{Developed software}

A primary aim of this research work was the development of a specialized software tool to efficiently and effectively conduct the necessary numerical simulations and parametric studies of seismically isolated buildings with automatic impact detection and handling capabilities. In particular, a software application has been developed, which is capable of performing efficiently two dimensional (2D) simulations of MDOF systems with shear-beam behaviour under dynamic loadings. In particular, an Object-Oriented Programming (OOP) approach and the Java programming language have been utilized to design and implement a flexible, robust and extendable software application with effective visualization capabilities (Figure 3) that can be used in relevant numerical simulations and parametric analyses.

The developed software application allows the consideration of poundings of a seismically isolated building, either with the surrounding moat wall or with one or more adjacent buildings. Moreover, the software allows both linear and bilinear models to be used for the simulation of the seismic isolation system. The 
ability to automatically perform large numbers of numerical simulations is also provided, in order to parametrically investigate the effects of certain parameters, such as the structural characteristics, the size of the separation gap and the earthquake characteristics.

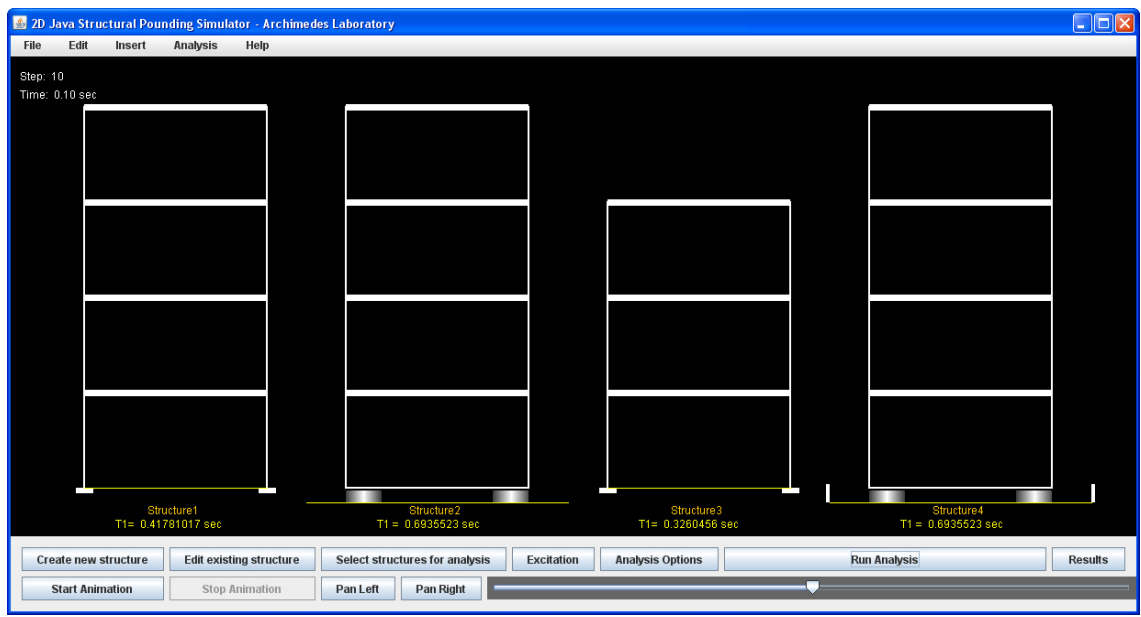

Figure 3: The main window in the graphical user interface (GUI) of the developed software application.

\subsection{Example}

A typical seismically isolated building is used in the simulations in order to examine the pounding effects on its seismic response. The superstructure is assumed to have 5 floors, each with a lamped mass of 320 tons, except of the top floor where a mass of 250 tons is considered. Each story has a horizontal stiffness of $600 \mathrm{MN} / \mathrm{m}$. An additional mass of 320 tons is assumed to be lumped at the isolation level, while the bilinear properties of the isolation system were taken as follows: $K_{I}=200 \mathrm{MN} / \mathrm{m}, K_{2}=25 \mathrm{MN} / \mathrm{m}, f_{y}=0.1 \times W_{\text {tot }}$, where $W_{\text {tot }}$ is the total weight of the building. A viscous damping ratio of $2 \%$ was assumed for the superstructure, while for the isolation system, in addition to the hysteretic energy dissipation, a $5 \%$ viscous damping ratio was considered. The fundamental period of the fixed-supported superstructure is equal to $\mathrm{T}_{\text {fixed }}=0.49 \mathrm{sec}$.

The structure is considered under two different circumstances. In the first case, the seismically isolated building is considered without the possibility of impacts, assuming a sufficiently wide seismic gap. In the second case a seismic gap width equal to $24 \mathrm{~cm}$, which is about $15 \%$ smaller than the maximum unobstructed induced relative displacement $(27.48 \mathrm{~cm})$ of the building under the San Fernando earthquake, is considered at the base, leading to pounding with the surrounding moat wall. The later is assumed to be completely rigid and move with the ground during an earthquake. The San Fernando, California USA earthquake 1971 , which is a very strong earthquake $(1.17 g)$, is used as ground excitation in the performed simulations. 
Figure 4 presents the relative displacement time-histories at the base of the seismically isolated building under the San Fernando earthquake for both the case without poundings and the case of a seismic gap equal to $24 \mathrm{~cm}$, where the base mat unavoidably hits against the surrounding moat wall, specifically at the time instance of $3.66 \mathrm{sec}$. It is observed that the differences in the two plots are very difficult to be identified, since only a slight reduction of the peak values due to impact can detected.

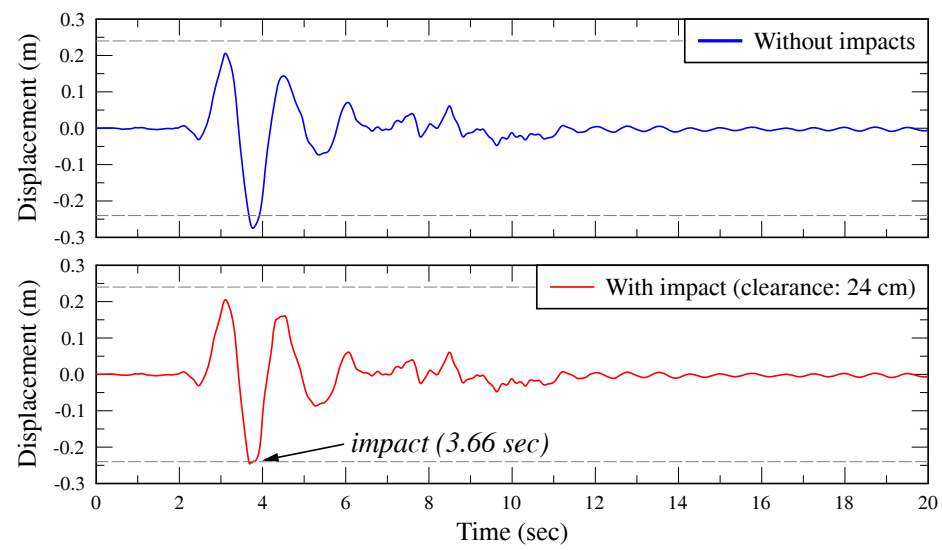

Figure 4: Relative displacement time-histories at the isolation level of the building, for the two cases of without and with poundings.

In contrast to the relative displacements responses, floor accelerations, as expected, are found to be more sensitive to impact occurrences. Although the width of the clearance is only $3.5 \mathrm{~cm}$ smaller than the maximum unobstructed relative displacement at that level, the effects of pounding are very apparent, especially on the acceleration response at the isolation level where impacts occur. Figure 5 presents the acceleration time-histories of the seismically isolated building during poundings, which are compared to the corresponding timehistories for the case without poundings. Very high accelerations are observed at the time of impact $(3.66 \mathrm{sec})$. In particular, the high spikes in the acceleration response reach up to 6 times the corresponding peak floor accelerations without poundings, in which case the response, as shown by the plot, is much smoother. Nevertheless, due to the structure's damping, short time after the impact occurrences, the response tends to become identical to the corresponding response without poundings.

The peak values of the interstory deflections and absolute floor accelerations of the seismically isolated building during impact are plotted in Figure 6 and compared with the corresponding values of the fixed-supported and base-isolated building without impacts. It is observed that, during poundings, interstory deflections at the upper floors are amplified up to 3 times due to poundings with the moat wall, compared to the case without poundings and reach the peak 

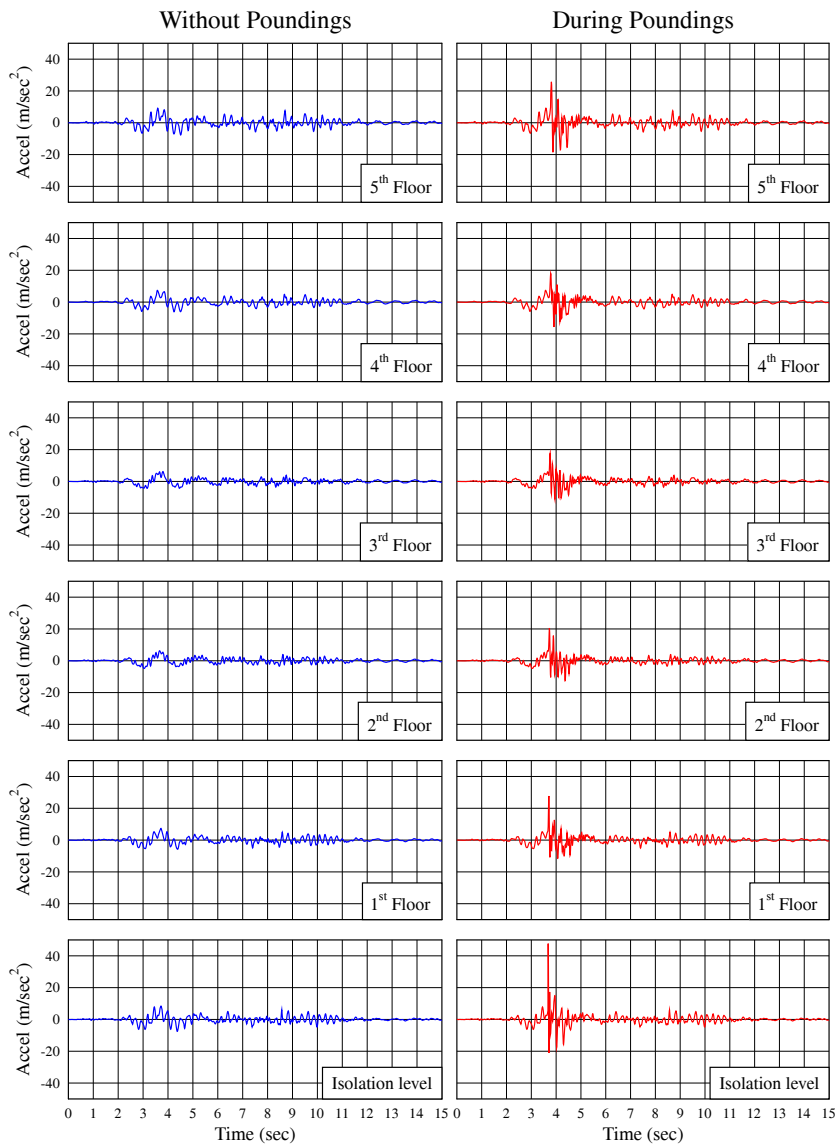

Figure 5: Acceleration time-histories at each floor level of the 5-story seismically isolated building, without and with poundings respectively.
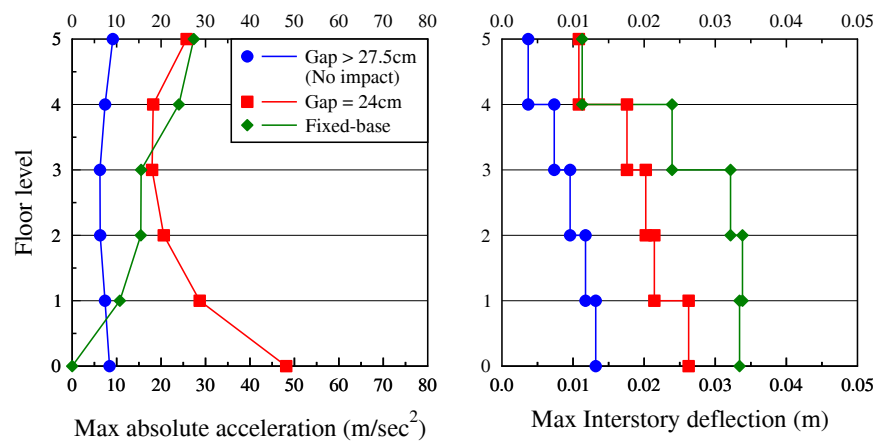

Figure 6: Peak floor accelerations and peak interstory deflections of the 5story seismically isolated building, for the cases of without and with pounding respectively. 
values of the deflections of the corresponding fixed-supported building. Consequently, almost the same shear forces that act on the corresponding fixedsupported building with the same characteristics, act on the particular stories of the superstructure. If not sufficient strength is provided to the structural elements, taking into account these effects of potential poundings during the design of the superstructure of the seismically isolated building, there is a great possibility of causing considerable damage in such cases.

Comparing the computed peak absolute floor accelerations of the building, the influence of poundings in the response is much more pronounced at the lower floors, where the peak floor accelerations become much higher than those for the corresponding fixed-supported building. Due to poundings with the moat wall, the seismically isolated building may experience maximum floor accelerations at the isolation level, where impacts occur, instead of the top-floor, which is the most common case for a MDOF system. It is well known from previous studies $[1,3]$ that the acceleration response is highly affected by impacts. These high values of floor accelerations that are caused by poundings can damage sensitive equipment that may be accommodated in the building.

In order to examine the effect of the seismic gap size on the response of the seismically isolated building during poundings with the moat wall, a parametric analysis has been conducted. In particular, the width of the seismic gap is varied from 10 to $45 \mathrm{~cm}$ with a step of $0.5 \mathrm{~cm}$, considering equal gap sizes on both sides of the building. The plots in Figure 7 present the peak floor accelerations and peak interstory deflections of the 5-story seismically isolated building under the San Fernando earthquake record, in terms of the width of the seismic gap. It is expected that, in general, as the seismic gap increases, both floor accelerations and interstory deflections of the superstructure would decrease. However, the simulation results indicate that for relatively narrow gap sizes the response increases with the width of the available clearance and after a certain value the response of the seismically isolated building begins to decrease, as rationally expected. This observation is more pronounced for the lower floors, which are closer to the impact location. This is due to the fact that for very narrow seismic
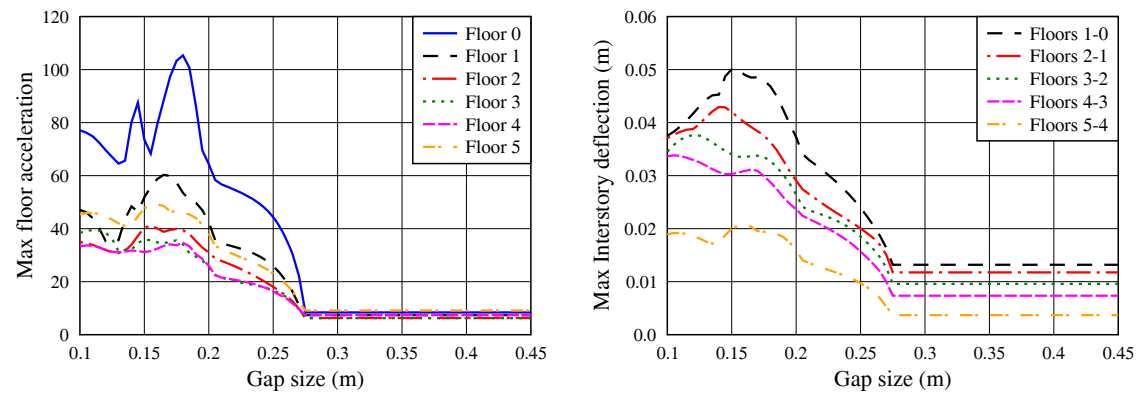

Figure 7: Peak floor responses of the 5-story seismically isolated building in terms of the width of the seismic gap. 
gap widths $(<15 \mathrm{~cm})$, in comparison with the maximum unconstrained induced displacement, the seismically isolated building retains relatively low impact velocities.

Figure 8 presents the total number of impacts and the maximum impact velocity at the isolation level of the 5-storey seismically isolated building, in terms of the seismic gap width. It is observed that the trend of the maximum impact velocity is very similar to the corresponding peak acceleration response of the seismically isolated building at the isolation level, indicating that the amplification of the response due to impact is proportional to the impact velocity. It is also observed that the total number of impacts is not always decreasing with the width of the seismic gap as it was expected, and seems to depend from the earthquake characteristics and the structural properties. Nevertheless, for gap sizes larger than $17 \mathrm{~cm}$ the peak floor responses, as well as the impact velocity decrease with the width of the seismic gap.
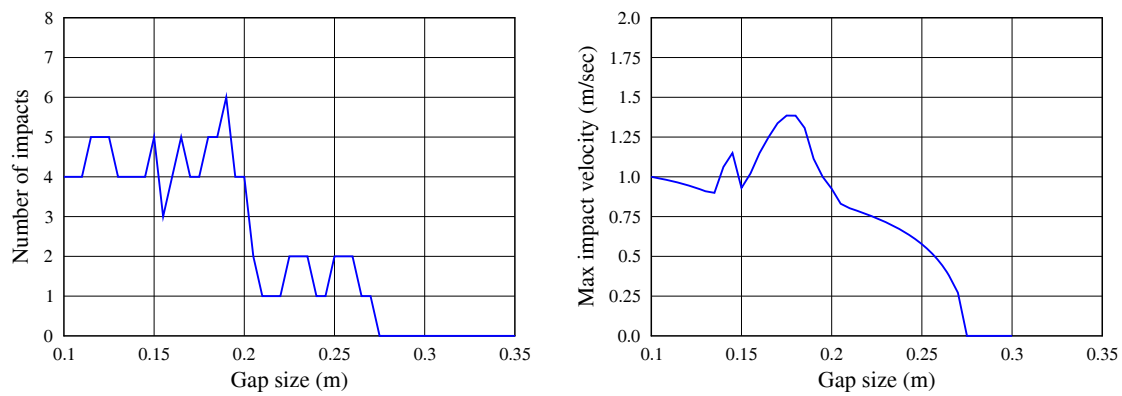

Figure 8: Total number of impacts and maximum impact velocity at the isolation level, in terms of the size of the seismic gap.

Another series of parametric studies is performed, in order to examine the effect of the impact stiffness and the coefficient of restitution on the peak response of a seismically isolated building during poundings, since the value of these impact parameters are usually based on estimations. The same building is considered under the same excitation, while the seismic gap is taken to be $24 \mathrm{~cm}$.

The plots in Figure 9 indicate that the effect of impact parameters is localized, since the only response quantity that seems to be substantially affected by the variation of these two parameters is the peak floor acceleration at the seismic isolation level, where impacts occur. In particular, the peak floor acceleration at that level increase very rapidly in contrary to the peak floor accelerations of the upper floors, which are slightly affected by the impact stiffness after a certain value of $k_{\text {imp }}$. Furthermore, the results show that, for values of the coefficient of restitution lower than 0.4 , the peak floor acceleration at the isolation level increases and reaches its maximum value when the impact becomes highly overdamped. The rest of the response remains insensitive to the variation of the coefficient of restitution, i.e. the impact damping. 

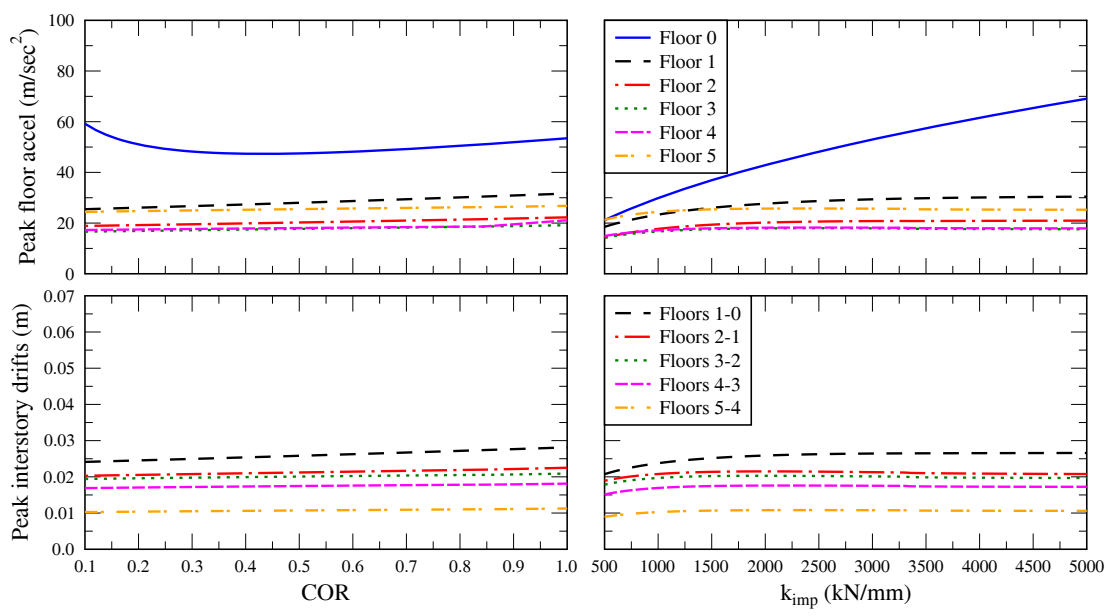

Figure 9: Influence of the impact parameters on the peak floor accelerations and interstory deflections.

\section{Conclusions}

A methodology has been presented that is used for simulating, in two dimensions, earthquake-induced pounding of seismically isolated buildings. A typical 5-storey building has been used as an example to demonstrate the most important effects of pounding on its structural response during a strong earthquake. The simulations show that poundings are particularly unfavourable for the structure and its contents, since they increase significantly the absolute floor accelerations and interstory deflections of the building. In particular, very high accelerations are observed at the times of impacts due to the sudden changes of the velocity, especially at the isolation level where impacts occur. These high values of induced floor accelerations can damage sensitive equipment that may be accommodated in the building. Furthermore, significant amplification of the storey shear-forces has been observed specially at the upper floors and if not sufficient strength is provided to the corresponding structural elements, there is a great possibility of considerable structural damage, in such cases.

\section{References}

[1] Anagnostopoulos, S.A. Pounding of buildings in series during earthquakes. Earthquake Engineering and Structural Dynamics, 16 pp. 443-456, 1988.

[2] Papadrakakis, M., Apostolopoulou, C, Zacharopoulos, A, Bitzarakis, S. Three-dimensional simulation of structural pounding during earthquakes. Journal of Engineering Mechanics, 122 pp. 423-431, 1996.

[3] Maison, B.F., Kasai, K. Analysis for Type of Structural Pounding. Journal of Structural Engineering; 116 pp. 957-977, 1990. 
[4] Anagnostopoulos, S.A., Spiliopoulos, K.V. An investigation of earthquake induced pounding between adjacent buildings. Earthquake Engineering and Structural Dynamics, 21 pp. 289-302, 1992.

[5] Chau, K.T., Wei, X.X. Poundings of structures modeled as non-linear impacts of two oscillators. Earthquake Engineering and Structural Dynamics, 30 pp. 633-651, 2001.

[6] Matsagar, V.A., Jangid, R.S. Seismic response of base-isolated structures during impact with adjacent structures. Engineering Structures, 25 pp. 13111323, 2003.

[7] Komodromos, P., Polycarpou, P.C., Papaloizou, L., Phocas, M.C. Response of Seismically Isolated Buildings Considering Poundings. Earthquake Engineering and Structural Dynamics, 36 pp. 1605-1622, 2007.

[8] Polycarpou, P.C., Komodromos, P. On poundings of a seismically isolated building with adjacent structures during strong earthquakes", Earthquake Engineering and Structural Dynamics (Published on-line) DOI: 10.1002/eqe.975, 2009. 